\title{
A Tale of 3 Asian Cities: How is Primary Care Responding to COVID-19 in Hong Kong, Singapore, and Beijing?
}

Samuel Y. S. Wong, MD, MPH

David H. Y. Tan, MBBS ${ }^{2}$

Yun Zhang, $M D^{3}$

Anbumalar Ramiab, MBBS 2

Xuejun Zeng, $M D, P b D^{3}$

Eric Hui, MBBS ${ }^{4}$

Doris Y. L. Young, MBBS, $M D^{5}$

'The Jockey Club School of Public Health and Primary Care, Chinese University of Hong Kong, Hong Kong

${ }^{2}$ National University Polyclinics, National University Health System, Singapore

${ }^{3}$ Peking Union Medical College Hospital, Chinese Academy of Medical Sciences, Beijing, China

${ }^{4}$ Department of Family Medicine, New Territories East Cluster, Hospital Authority, Hong Kong

${ }^{5}$ Yong Loo Lin School of Medicine, National University of Singapore, Singapore

Conflicts of interest: authors report none.

\section{CORRESPONDING AUTHOR}

Samuel Y.S. Wong, MD, MPH

The Jockey Club School of Public

Health and Primary Care

Chinese University of Hong Kong

Rm409, 4/F School of Public Health

Prince of Wales Hospital

Shatin, New Territories, Hong Kong

Special Administrative Region

yeungshanwong@cuhk.edu.hk

\begin{abstract}
Hong Kong, Singapore, and Beijing have some of the highest numbers of international arrivals and densest living spaces globally, yet these cities have reported low numbers of deaths amid the coronavirus disease 2019 (COVID-19) outbreak. Primary care has played different roles in each of the health systems in combatting the pandemic. Both Hong Kong and Singapore have a 2-tiered health system with the majority of primary care provided in the private sector. The primary care system in Beijing consists of community health facilities, township health centers, and village clinics. The role of primary care in Hong Kong includes using the public primary care clinics as part of an enhanced surveillance program together with accident and emergency departments, as well as triaging patients with suspected infection to hospitals. Singapore's response to COVID-19 has included close cooperation between redeveloped polyclinics and private and public health preparedness clinics to provide screening with swab tests for suspected cases in the primary care setting. Beijing's unique response has consisted of using online platforms for general practitioners to facilitate monitoring among community residents, as well as public health education and a mobilized pharmacy refill program to reduce risk of transmission. Established challenges, however, include shortages of personal protective equipment and the heavy workload for health care staff. Regardless, all 3 cities have demonstrated enhanced preparedness since experiencing the severe acute respiratory syndrome epidemic, and the responses of their primary care systems therefore may offer learning points for other countries during the COVID-19 pandemic.
\end{abstract}

Ann Fam Med 2021;19:48-54. https://doi.org/10.1370/afm.2635.

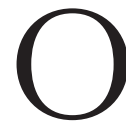
n January 30, 2020, the World Health Organization (WHO) declared coronavirus disease 2019 (COVID-19) to be a public health emergency of international concern. ${ }^{1}$ As of December 19, 2020, there have been 73, 996, 237 confirmed cases of COVID-19 reported to $\mathrm{WHO}$, including 1,663,474 deaths. The COVID-19 pandemic follows on the 2002-2003 outbreak of severe acute respiratory syndrome (SARS) and the 2009 outbreak of (H1N1)pdm09 virus (H1N1) influenza, both of which also had substantial impact in Asia and its major cities.

Hong Kong is a Special Administrative Region of the People's Republic of China. Situated in southern China and separated by a $19-\mathrm{km}$ border, it recorded 12,137,924 non-mainland tourists in 2019 alone and has more than 100,000 arrivals from mainland China per day. ${ }^{2}$ Hong Kong has a population of 7.45 million and the 8 th busiest airport in the world. The first COVID-19 case in this region was reported on January 23, 2020, and as of July 15,2020, a total of 1,589 cases were confirmed, with 10 deaths. ${ }^{3}$

Singapore is an island city-state and country located at the southern tip of the Malay Peninsula off southern Malaysia, consisting of Singapore Island and 60 small islets. It has a population of 5.7 million, and from January to September 2019, Singapore recorded 14.3 million international visitor arrivals ${ }^{4}$ in the tourism sector alone. The border in the north of Singapore with Malaysia is one of the busiest land border checkpoints in the 
world, with more than 450,000 people crossing daily using the 2 land crossings spanning the Straits of Johor. The first COVID-19 case in Singapore was reported on January 23,2020 , and as of July 15 , 2020 , a total of 46,878 cases and 27 deaths were confirmed. ${ }^{5}$

Beijing is the capital of the People's Republic of China. It is the most populous capital city in the world, with more than 21 million residents living in an area of $16,410.5 \mathrm{~km}^{2}$. It is a major hub for China's highway, expressway, railway, and high-speed rail networks. Beijing Capital International Airport is the second busiest airport in the world for passenger traffic, and the city's subway network is the busiest and longest in the world. The first COVID-19 case in Beijing was reported on January 20, 2020, and as of July 15,2020, a total of 929 cases were confirmed, with 9 deaths. ${ }^{6}$

Hong Kong, Singapore, and Beijing have done relatively well in controlling the spread of COVID-19, and primary care has been part of a larger coordinated response to combat this threat (Table 1). As the disease has become a pandemic $_{,}^{8}$ understanding the role and response of primary care in each city can provide learning points for other countries.

\section{CITY-SPECIFIC EXPERIENCES}

\section{Hong Kong: Learning From SARS}

Hong Kong has a 2-tiered primary care system with about $70 \%$ of primary care services provided by the private sector. Thirty percent of primary care is provided by the 73 public General Outpatient Clinics (GOPCs) of the Hospital Authority ${ }^{9}$ (Table 2). GOPCs mainly provide primary care services for older adults, people with chronic conditions, and those of lower socioeconomic status. ${ }^{13}$ As many private primary care clinics were not prepared to respond to the pandemic because they lacked personal protective equipment (PPE) or space, the role of GOPCs has expanded to include gatekeeping and surveillance at this time. ${ }^{16}$

In the wake of the SARS outbreak in 2002-2003, Hong Kong has strengthened its ability to prepare for emerging infectious disease outbreaks, including setting up the Centre of Health Protection ${ }^{17}$ and using designated public primary care clinics to manage patients' infectious disease symptoms during community outbreaks. Most primary care clinics also created a fever room to isolate and manage patients with fever and thereby reduce transmission. There were about 498,630 total visits to GOPCs in 2018 alone, ${ }^{18}$ with each physician seeing 74 patients per day. ${ }^{18}$

Since the Hospital Authority activated the emergency response level, health professionals in PPE are stationed at the entrance of every GOPC to identify high-risk patients by checking body temperature and travel history, and to segregate them into the fever cohort area for early medical assessment. Patients suspected to have COVID-19 are transferred by ambulance to local hospitals for early testing and treatment. ${ }^{19}$ There is no designated triage clinic in the public system, and patients can get tested with the deep throat saliva test for severe acute respiratory syndrome coronavirus 2 (SARS-CoV-2) in any of the public GOPCs, in accident and emergency departments, and in private clinics. A recent survey by the Hong Kong College of Family Physicians showed reduced use of clinical services, especially in the private sector. ${ }^{16}$ Use of alternative strategies for patient engagement in primary care is not prevalent in public or private primary care clinics, although relatives or friends with proof 
of the patient's identification are permitted to visit public primary care clinics on patients' behalf to obtain their prescribed medicine. Together with accident and emergency departments, the GOPCs have formed part of an enhanced surveillance program ${ }^{20}$ for providing needed information on the severity of community outbreaks. In this program, physicians give patients with fever and mild respiratory symptoms who do not have the relevant travel history the deep throat saliva test. From January 1 to July 14, 2020, a total of 442,256 people were tested, of whom 1,570 (0.4\%) were found to be positive for SARS-CoV-2.

\section{Singapore: Learning From Previous Pandemics} Similar to the system in Hong Kong, Singapore's primary care system is divided into private and public sectors, with about $80 \%$ of primary care services provided by private practitioners working in solo general practice clinics and multiphysician group practices (Table 2). They mainly attend to acute conditions. The remaining $20 \%$ of primary care is delivered by 20 public primary care clinics, or polyclinics, which are run with government support, allowing patients to receive care with a fair amount of government subsidies. Although the polyclinics provide a small fraction of primary care services, they provide up to $55 \%$ of all chronic disease management in Singapore, as they are well positioned to do so with their multidisciplinary setup. ${ }^{21}$ The private general practitioners receive extra training and support through the primary care networks, where resources to manage the chronic disease burden are provided. ${ }^{22}$

\section{Table 2. Primary Care Structure in Each City}

\begin{tabular}{|c|c|c|c|}
\hline Measure & Hong Kong & Singapore & Beijing \\
\hline \multicolumn{4}{|l|}{ Registered physicians } \\
\hline Registered physicians, No. & $14,700^{10}$ & 14,334 & 115,771 \\
\hline $\begin{array}{l}\text { Primary care physicians working in } \\
\text { public health centers, No. }\end{array}$ & $429^{13}$ & 455 & $32,298^{a}$ \\
\hline Private primary care physicians, No. & $2,476^{14}$ & 1,434 & $\ldots$ \\
\hline Public primary care health centers, No. & $73^{9}$ & 20 & 10,306 \\
\hline Ratio of public to private outpatient visits & $30: 70^{15}$ & $20: 80$ & $\ldots$ \\
\hline \multicolumn{4}{|l|}{$\begin{array}{l}\text { Structure of public primary care } \\
\text { health centers }\end{array}$} \\
\hline Location & $\begin{array}{l}\text { Independent clinics or within } \\
\text { public hospital grounds }\end{array}$ & $\begin{array}{l}\text { Independent buildings or } \\
\text { within integrated develop- } \\
\text { ments in the community }\end{array}$ & Mostly independent clinics \\
\hline Funding & Public funding & $\begin{array}{l}\text { Public funding with copayment } \\
\text { in cash out of pocket or } \\
\text { through Medisave }\end{array}$ & Public funding \\
\hline Practice size & 2 to 20 & 10 to 30 & $\begin{array}{l}\text { At least } 2 \text { to } 6 \text { (flexible based } \\
\text { on number of residents in } \\
\text { community) }\end{array}$ \\
\hline Relationship to public health & Separate entities & Separate entities & Integrated system \\
\hline Referral process & $\begin{array}{l}\text { Referral to specialist out- } \\
\text { patient clinics of public or } \\
\text { private clinics/hospitals }\end{array}$ & $\begin{array}{l}\text { Referral to specialist outpatient } \\
\text { clinics of public hospitals }\end{array}$ & $\begin{array}{l}\text { Referral to specialist (including } \\
\text { physicians with GP certificates) } \\
\text { outpatient clinics of hospitals }\end{array}$ \\
\hline \multicolumn{4}{|l|}{$\begin{array}{l}\text { Structure of private primary care } \\
\text { health centers }\end{array}$} \\
\hline Location & $\begin{array}{l}\text { Independent clinics or within } \\
\text { private hospital grounds }\end{array}$ & Mainly independent clinics & $\ldots$ \\
\hline Funding & Out of pocket or insurance & $\begin{array}{l}\text { Out of pocket, insurance (self } \\
\text { or employer), or public fund- } \\
\text { ing (CHAS) }\end{array}$ & $\ldots$ \\
\hline Practice size & Solo or small group & Solo or small group & $\ldots$ \\
\hline Relationship to public health & Separate entities & Separate entities & $\cdots$ \\
\hline Referral process & $\begin{array}{l}\text { Referral to specialist out- } \\
\text { patient clinics in public or } \\
\text { private clinics/hospitals }\end{array}$ & $\begin{array}{l}\text { Referral to specialist outpatient } \\
\text { clinics in private clinics/hos- } \\
\text { pitals or (only for those on } \\
\text { CHAS) public clinics/hospitals }\end{array}$ & $\cdots$ \\
\hline \multicolumn{4}{|c|}{ CHAS = Community Health Assistance Scheme; GP = general practitioner. } \\
\hline \multicolumn{4}{|c|}{ Note: all data for Singapore from Singapore Medical Council1"1; all data for Beijing from Beijing Municipal Health Commission Policy Research Center. ${ }^{12}$} \\
\hline \multicolumn{4}{|c|}{$\begin{array}{l}\text { a The figures are total numbers (both the public and the non-public included). The primary care system in Beijing is largely publicly funded. Only a small number of } \\
\text { institutions are non-publicly funded, and to our knowledge, there has not been any official statistics released on this part. }\end{array}$} \\
\hline
\end{tabular}


With their larger facilities, the government polyclinics are well equipped with PPE and have segregation areas where patients with potentially infectious diseases can be seen. All new and redeveloped polyclinics have been constructed with this possibility in mind, given that Singapore recognized the need for infectious disease segregation from its experience with the SARS and H1N1 outbreaks, which required setting up temporary fever tents. Since the H1N1 outbreak in 2009, government polyclinics and certain private general practitioner clinics identified as Public Health Preparedness Clinics can be activated to provide the general population with subsidized consultations for respiratory conditions arising from disease outbreaks and environmental pollution. Activation of the these clinics and government subsidies for care related to acute respiratory infections encourages patients with symptoms to visit primary care clinics. The advent of telemedicine was given a boost as clinicians tapped into technology to remotely see patients who required care but for whom there are concerns about a face-to-face visit. General practitioners and polyclinics have reported a fall in visits during lockdown measures to reduce community transmission, but are seeing numbers returning to prepandemic levels after the lifting of such measures.

With the latest COVID-19 outbreak, the polyclinics and selected Public Health Preparedness Clinics have also been performing SARS-CoV-2 swab tests to help alleviate the workload for tertiary centers. As of July 13, 2020, a total of 1,009,532 swab tests had been performed to test for SARS-CoV-2, giving a swab rate of 17,711 per 100,000 total population.

The early phase of the COVID-19 outbreak included patients who were tourists from Wuhan. On February 3, 2020, cases of local transmission started appearing, and by February 8, locally transmitted cases exceeded imported ones. March saw a surge in imported cases as overseas Singapore residents started returning, with each country imposing its own restrictions; in April, local cases once again surpassed imported cases with dormitories of foreign workers seeing large clusters form and quickly overtake community-transmitted cases.

Close cooperation between primary care practitioners in both the private sector and public sector ${ }_{1}^{23}$ together with involvement of the professional bodies, such as the College of Family Physicians Singapore, the Singapore Medical Association, and the Academy of Medicine Singapore, allowed quick dissemination of information, advisories, and instructions between the authorities and medical practitioners. Government polyclinics were enlisted to help perform N95 mask fitting for private general practitioners, and polyclinics currently serve as referral centers for cases that satisfy specific COVID-19 swab criteria from general practitioners who are not performing their own swab tests.

\section{Beijing: Increasing the Role of Primary Care in Public Health Functions Since SARS and National Health Reform}

Beijing has a unique primary care system when compared with other cities in China (Table 2). The primary care system has been evolving for decades and is now a fledgling industry consisting of community health facilities, township health centers, and village clinics. Rural areas are primarily served by township health centers and village clinics, whereas urban areas are mainly served by community health facilities. ${ }^{24}$ Since the SARS outbreak in 2003, together with the comprehensive medical reform in 2009, Beijing's primary health care has become relatively well developed within the mainland. ${ }^{25}$ Previous experience with SARS had highlighted the importance of primary health care, and the need for increased financial support and better training. Nowadays, primary health care has taken a larger part in the provision of health care services and has adopted the gatekeeper role with an emphasis on the management of chronic diseases, disease prevention, and public health. ${ }^{12,26}$

Although the role of primary health care has increased in Beijing, the city's large population continues to lead to a relative shortage of general practitioners. Based on statistics from 2018, the primary care system accounts for $53.1 \%$ of overall medical encounters, yet the average number of general practitioners has reached only 2.22 per 10,000 capita. The country has therefore seen a surge of pressure on the health care system during the COVID-19 outbreak. Throughout mainland China, most primary care facilities $(92.2 \%)$ have been working around the clock to alleviate the pressure on health care services. Many have extended new functions in public health as a response to the epidemic. Working in conjunction with designated hospitals and other institutions to control the coronavirus, $51 \%$ have opened fever clinics and more than $80 \%$ participate in patient triage.

Beijing promptly activated the first-level public health emergency response on January 24, 2020, when there were 29 confirmed COVID-19 cases. General practitioners have taken on the dual tasks of disease surveillance and public health education, including the monitoring and following up of community residents with potential disease contact, testing and screening, and providing preventive strategies to the public. Information technology has further extended general practitioners' roles by enabling better patient accessibility. Interactions between patients and health care practitioners have been facilitated via various online 
platforms, making it easier for clinicians to communicate with, track the condition of, and educate community residents. A district in Beijing has launched a mobile pharmacy program using an online platform to streamline the process of getting medication refills, with the intent of reducing the contact time and the risk of cross-infection.

Against the backdrop of COVID-19, the National Health Commission of the People's Republic of China made a new announcement on July 13, 2020, emphasizing the goal of building community health facilities with both disease prevention and treatment functions. ${ }^{27}$ These strategies include enhancing the training and reporting system to ensure early detection and prompt reporting of infectious diseases, and strengthening of the support for vulnerable people, including those returning home after recovery from COVID-19. Community health facilities also should provide health care workers with adequate proper protective and preventive equipment, and should provide public health information and education to residents to prepare for future pandemics.

\section{CHALLENGES}

Cities face both similar and differing challenges in responding to the pandemic. Hong Kong has a shortage of PPEs, mainly in private clinics. As many general practitioners are solo practitioners with only limited staff, a large share of general practitioner clinics are not equipped with enough PPE, space, or manpower to manage patients potentially infected with COVID19 , which often requires temperature screening of all patients, triaging, and isolation of symptomatic patients. Because of these barriers, some private clinics were closed during the peak of the COVID-19 pandemic. ${ }^{16}$ Public clinics have more support in manpower resources, space, and PPE from the public health care service system. There is also a coordinated emergency response system whereby GOPCs become designated fever clinics when the community outbreak hits a prespecified severity level. Because of a lack of trust and understanding about the nature of the designated clinics, however, the general public has resisted visiting these clinics for fear of spreading the infection to the community. Up to the present, no designated clinics have been opened. Other challenges include the availability and arrangement of point-of-care test kits for private general practitioners to assist in testing.

In Singapore, the shortage of PPE seems to have been managed appropriately by the authorities and the primary care networks. With uncertainty about the possible duration of the pandemic, however, future supply of PPE could be in doubt and its use will still need to be rationed. As a result, health care professionals are at risk for exposure to asymptomatic or presymptomatic patients, especially when they are outside fever zones without the full protection of N95 masks, gowns, and goggles, and patients present for other nonrespiratory symptoms. Although primary care is stepping up in Singapore to assist with swab testing, this effort is limited by the constraints seen in many general practitioner clinics, which may not have facilities such as well-ventilated rooms to carry out swab testing safely. The return of patients who initially avoided seeking care during lockdown measures is also adding to the workload of primary care practitioners, who are already busy with responsibilities of assessing and testing patients at risk for COVID19. Primary care physicians will have to reexamine their current protocols and timing norms to better manage the return of patients seeking chronic care, together with the ongoing pandemic requirements and responsibilities.

Other continuing challenges are making point-ofcare test kits available for primary care practitioners to quickly identify infected patients, as well as ensuring speedy medical transportation of certain subgroups of swab-tested patients to isolation facilities for further management. The large number of foreign workers housed in dormitories in Singapore is also a cause for concern, as there have been several clusters of outbreaks in these facilities. Time will tell if Singapore's multipronged approach, which includes ongoing public education, expanded swabbing criteria, extensive contact tracing measures, mask-wearing requirements, and restrictions on gatherings, will prevent a second wave of infections.

In Beijing, the increased demand for primary care services and the enhanced coordination needed between the primary care and hospital systems have proven to be challenging. One of the biggest challenges is the workload. The number of people who need to be screened, tested, and quarantined is overwhelming. Beijing, having learned from the experience of combating SARS in 2003, is now more prepared than most other cities in mainland China. The communications between general practitioners and health care staff working in higher-level hospitals have further strengthened their ability to cope with COVID-19. Although many are engaged in efforts to curtail the pandemic, they also have to run the regular health care services, accentuating the mismatch between the increased workload and the relatively small number of primary care workers. More support is therefore needed to solve these problems.

Aging has posed yet another challenge. The proportion of elderly people in Beijing hit 25.4\% at the 
end of 2018, and it is still rising. General practitioners in the communities provide health care services to this population, conducting routine workups and managing chronic illnesses. During the pandemic, however, provision of regular health care services has been undermined. The government is now pushing for new ways to help ensure health care for older adults with the use of online platforms to facilitate physician-patient communications. Yet, even better solutions are needed in the future for the vulnerable populations.

\section{LESSONS LEARNED}

Hong Kong and Singapore have similar primary care systems and therefore share common approaches and challenges in how they have responded to COVID19. In both cities, government clinics have played an important role in testing and triaging potentially infected people in the community, although with the recent development of the general practitioner network in Singapore, there are now closer collaborations between public and private clinics to share the work with a more coordinated response between these sectors. ${ }^{23}$ The increase in service demand appears to be the biggest challenge in Beijing, where there is a lack of primary care clinicians to meet the demand for both COVID-19 care and elderly care, reflecting the city's underlying ongoing issue of a shortage of primary care physicians. Despite differences in their primary care systems, all 3 cities have made use of primary care in performing both public health functions (surveillance) and primary care functions (triaging and managing suspected cases), and have implemented strict infection control protocols to avoid cross-infection.

Effective control of COVID-19 requires efforts from the government, the community, and all sectors. Primary care is an indispensable part of any health system, and when it is adequately supported (eg, with sufficient PPE supply), engaged, and integrated with other parts of a health system, primary care can play a key role during a pandemic. Strengthening primary care should therefore be made a priority for any country to enhance the overall health system response, to deal with any future infectious disease outbreaks.

\section{CONCLUSIONS}

Hong Kong, Singapore, and Beijing have learned from the SARS and H1N1 outbreaks and appear to be better prepared for the COVID-19 pandemic when compared with other countries in terms of overall strategies for controlling the spread of the virus. Primary care has played the roles of testing, surveillance, and triaging of suspected cases to hospitals from the community for further management. Challenges identified include ensuring adequate supply of PPEs and testing kits, and the need to enhance communication between primary care clinicians and health authorities so that adequate support and information regarding COVID-19 is provided to frontline primary care physicians rapidly.

To read or post commentaries in response to this article, see it online at https://www.AnnFamMed.org/content/19/1/48.

Key words: COVID-19; coronavirus; infectious diseases; pandemics; disease outbreaks; primary care system; primary care; health services; professional practice

Submitted April 30, 2020; submitted, revised, July 23, 2020; accepted August 5, 2020.

\section{References}

1. World Health Organization. COVID-19 Public Health Emergency of International Concern (PHEIC) Global research and innovation forum. https://www.who.int/publications/m/item/covid-19-public-healthemergency-of-international-concern-(pheic)-global-research-andinnovation-forum. Published Feb 12, 2020. Accessed Apr 6, 2020.

2. Hong Kong Tourism Board Research. Hong Kong monthly report - visitor arrival statistics: Dec 2019. https://partnernet.hktb. com/filemanager/intranet/pm/VisitorArrivalStatistics/ViS_Stat_E/ VisE_2019/Tourism\%20Statistics\%2012\%202019.pdf. Published Jan 2020. Accessed Apr 6, 2020.

3. Centre for Health Protection. 2020. Latest situation of coronavirus disease (COVID-19) in Hong Kong. https://chp-dashboard.geodata. gov.hk/covid-19/en.html. Accessed Jul 16, 2020.

4. Singapore Tourism Board. Tourism sector performance for Q3 2019 report. https://www.stb.gov.sg/content/dam/stb/documents/ statistics-marketing-insights/Quarterly-Tourism-Performance-Report/ STB-Q3-2019-Tourism-Performance-report-FINAL.pdf. Accessed Apr 19,2020

5. Ministry of Health. Singapore. Updates on COVID-19 (Coronavirus disease 2019) local situation. https://www.moh.gov.sg/covid-19. Accessed Jul 16, 2020.

6. Sina International News. Updates on COVID-19 in Beijing (in (Chinese). https://news.sina.cn/project/fy2020/yq_province.shtml? province $=$ beijing $\delta w m=3049 \_0135 \&$ from $=$ groupmessage $\varepsilon$ isapp installed $=0$. Accessed Jul 16, 2020.

7. Xinhua News Agency. The number of Beijing nucleic acid tests exceeds 11 million and 54 communities are released from control. https://www.gov.cn/xinwen/2020-07/06/content_5524603.htm. Published Jul 6, 2020. Accessed Jul 16, 2020.

8. World Health Organization. Coronavirus disease (COVID-19) pandemic. https://www.who.int/emergencies/diseases/novel-coronavirus-2019. Accessed Apr 6, 2020.

9. LCQ4: General out-patient services under hospital authority. News release. The Government of Hong Kong Special Administrative Region. https://www.info.gov.hk/gia/general/201804/25/P20180425 00638.htm. Published Apr 25, 2018. Accessed Apr 6, 2020.

10. Medical Council of Hong Kong. List of registered medical practitioners. https://www.mchk.org.hk/english/list_register/list.php?page = 1 Eipp $=20$ Etype $=$ SEfromlist $=$ YEadvancedsearch $=Y$ Eregno $=$ SO5. Accessed Jul 16, 2020.

11. Singapore Medical Council. Annual report 2018. https://www.health professionals.gov.sg/docs/librariesprovider2/publications-newsroom/ smc-annual-reports/2018-smc-annual-report.pdf. Accessed Jul 16, 2020.

12. Beijing Municipal Health Commission Policy Research Center. Beijing health service statistical yearbook 2019 (in Chinese). https://www. phic.org.cn/tjsj/wstjjb/202007/U020200709520817963350.pdf. Accessed Jul 18, 2020 
13. LCQ8: General out-patient services. News release. The Government of Hong Kong Special Administrative Region. https://www.info.gov. hk/gia/general/201801/10/P2018011000225.htm. Published Jan 19, 2018. Accessed Apr 6, 2020.

14. Food and Health Bureau. List of enrolled primary care providers. https://www.pcdirectory.gov.hk/english/pcproviders/index.html. Accessed Jul 16, 2020.

15. Hong Kong Health Authority. Primary care development in Hong Kong; HA convention 2015. https://www3.ha.org.hk/haconvention/ hac2015/proceedings/downloads/MC10.2.pdf. Published May 19, 2015. Accessed Jul 16, 2020.

16. Yu EYT, Leung WLH, Wong SYS, Liu KSN, Wan EYF; HKCFP Executive and Research Committee. How are family doctors serving the Hong Kong community during the COVID-19 outbreak? A survey of HKCFP members. Hong Kong Med J. 2020;26(3):176-183.

17. Food and Health Bureau. Monitoring committee on implementation of the SARS expert committee report's recommendations, establishment of a centre for health protection in Hong Kong: implementation plan. https://www.fhb.gov.hk/download/press_and_publications/otherinfo/040121_sars_recom/sars_mc2-04_chp.pdf. Published Jan 19, 2004. Accessed Apr 6, 2020.

18. Department of Health. Health facts of Hong Kong, 2019 edition. https://www.dh.gov.hk/english/statistics/statistics_hs/files/Health_ Statistics_pamphlet_E.pdf. Accessed Apr 6, 2020.

19. LCQ12: Doctors working in general outpatient clinics. News release. The Government of Hong Kong Special Administrative Region. https://www.info.gov.hk/gia/general/200801/30/P200801300123. htm. Published Jan 30, 2008. Accessed Apr 6, 2020.
20. Public hospital daily update on Wuhan-related cases. News release. The Government of Hong Kong Special Administrative Region. https://www.info.gov.hk/gia/general/202001/31/P2020013100713. htm. Published Jan 31, 2020. Accessed Mar 18, 2020.

21. Ministry of Health. Primary healthcare services. https://www. moh.gov.sg/home/our-healthcare-system/healthcare-services-andfacilities/primary-healthcare-services. Accessed Apr 14, 2020.

22. Ministry of Health. Primary care networks. https://www.moh.gov. sg/home/our-healthcare-system/healthcare-services-and-facilities/ primary-care-networks. Accessed Apr 14, 2020

23. Lim WH, Wong WM. COVID-19: notes from the front line, Singapore's primary health care perspective. Ann Fam Med. 2020;18(3): 259-261.

24. Li X, Lu J, Hu S, et al. The primary health-care system in China. Lancet. 2017:390(10112):2584-2594

25. Yip WC, Hsiao WC, Chen W, Hu S, Ma J, Maynard A. Early appraisal of China's huge and complex health-care reforms. Lancet. 2012;379 (9818):833-842.

26. Beijing Municipal Health Commission Policy Research Center. Volume and efficiency of health service in Beijing during 2004-2019. http://www.phic.org.cn/tjsj/wssjzy/yljgjwsfwqk/. Accessed Dec 21, 2020.

27. The National Health Commission of the People's Republic of China. Notice of the National Health Commission on comprehensively promoting the construction of community hospitals. https://www.nhc. gov.cn/jws/s3581/202007/2aab83700656411e91b35ae9049dc732. shtml. Published Jul 13, 2020. Accessed Jul 20, 2020. 